\title{
Information-seeking behavior and use of social science faculty studying stateless nations: a case study
}

\author{
Lokman I. Meho*, Stephanie W. Haas \\ School of Information and Library Science, University of North Carolina at Chapel Hill, \\ CB \#3360, 100 Manning Hall, Chapel Hill, North Carolina 27599-3360, USA. \\ E-mail address:mehol@ils.unc.edu (L.I. Meho).
}

\begin{abstract}
The information-seeking behavior of social science faculty studying the Kurds was assessed using a questionnaire, citation analysis, and follow-up inquiry. Two specific questions were addressed: how these faculty locate relevant government information and what factors influence their seeking behavior and use of such information. Results show that besides using traditional methods for locating relevant government information, social science faculty studying the Kurds use the World Wide Web (Web) and electronic mail (e-mail) for that purpose, suggesting that these faculty are aware of, and utilize, new information technology to support their research. Results also show that the information-seeking behavior of social science faculty studying the Kurds is influenced by factors similar to those influencing other social science faculty. Moreover, results also show that accessing the needed materials is a major information-seeking activity that should be added to David Ellis' behavioral model, and that faculty examined here employ somewhat a more elaborate "differentiating" information-seeking activity than the one described in the model. Some elements of interdisciplinarity of Kurdish studies as a field of research have been discovered, however, further research is required to verify that. Implications for library services and suggestions for future research are presented. (C) 2001 Elsevier Science Inc. All rights reserved.
\end{abstract}

\section{Introduction}

Over the last few decades, various categories have been developed by researchers and others to describe the world and its population, for example, "East" vs. "West," "North" vs. "South," and "developed nations" vs. "developing nations." Another category that has

\footnotetext{
* Corresponding author.
} 
recently been frequently mentioned in the media and academic circles is "stateless nations" (e.g., the Basques, Chechens, Kashmiris, Kurds, Quebecois, Scots, Southern Sudanese, Tamils, and Tibetans) as opposed to nations with states (e.g., France, Germany, and the U.S.). Much research has been and still is being conducted on stateless nations, however, little, if any, is known about the information-seeking behavior of scholars who conduct this research. Traditional information-seeking behavior studies have primarily focused on the information needs, seeking behavior, and use of scholars in the context of their departmental affiliation, such as studying anthropologists, historians, and political scientists. In contrast, the information-seeking behavior of scholars in the context of their research topics has rarely been examined by library and information science researchers. Adequate knowledge about the information-seeking behavior of scholars studying stateless nations not only will enhance our knowledge about these scholars' particular information-seeking experiences but it is also necessary to assist libraries and other information centers in reorienting their collections, services, and activities to synchronize them with the information needs and seeking behavior of scholars studying stateless nations.

This study uses a questionnaire, citation analysis, and follow-up inquiry to examine how social science faculty studying one particular stateless nation, the Kurds, look for government information and what factors influence their seeking behavior and use of such information. In this study, social science faculty are considered as those individuals who conduct research in the fields of anthropology, area studies, communication, economics, education, geography, history, political science, psychology, sociology, women's studies, or a combination of two or more of these fields. Social science faculty were selected because the bulk of government information available on stateless nations is concerned with their history, politics, and social life, the subject areas intensely covered by faculty in social sciences departments.

The term "stateless nations" as used here is understood to mean those people who share a common heritage and distinctive culture and have a strong sense of national identity but are now subservient to other states. The topic of stateless nations, further discussed below, was chosen simply because it has never been researched in library and information science. Government information is understood to mean "any item, produced by reprographic or any other method, issued by an organisation that is an official body, and available to an audience wider than that body." Examples of official bodies include any legislature or executive agency of a state or federation of states or of a province, state, or regional, local, or other administrative subdivision (Johansson, 1982, pp. 393-395). The examination of social science faculty information-seeking behavior in the context of their use of government information was driven by the fact that government information is considered a major source of primary information on stateless nations and, in some cases, is the only source of information on stateless nations, as is illustrated in the case of the Kurds.

Information-seeking behavior is a broad term encompassing the ways individuals articulate their information needs, seek, evaluate, select, and use information. In other words, information-seeking behavior is a purposive seeking for information as a consequence of a need to satisfy some goal. In the course of seeking, the individual may interact with people, manual information systems, or with computer-based information systems (Wilson, 2000). Information use is a behavior that leads an individual to the use of information in order to meet his or her information needs. Information use is an indicator of information needs, but 
they are not identical. As Line (1973) points out, individuals do not use all information they need (partly because they are not always able to obtain what they need, partly because the materials may not be relevant when they obtain them, and partly because individuals sometimes do not know what they need). In addition, sometimes, individuals do not need all they use.

Knowledge about the information-seeking behavior and information use of social science faculty conducting research on stateless nations is crucial for effectively meeting their information needs. This knowledge may also lead to the discovery of novel information behaviors and user profiles that can be used to enhance existing information models or even develop new ones. Moreover, for librarians and other information professionals to be effective information providers, they require a fuller understanding of the informationseeking behavior, needs, and uses of these scholars. This article describes how social science faculty studying the Kurds look for government information. It also identifies the reasons for using and not using this information and the barriers to the use of this information.

\section{Stateless nations and the Kurds}

Today, there are more than 200 major stateless nations around the world. These nations have been denied independent states and been maneuvered into minority status in their home countries by colonial and imperial powers in the nineteenth and twentieth centuries. In varying degrees, these peoples resent their subservience, and they struggle, sometimes covertly and often overtly, to achieve political independence and, hence, to have the right to self-determination (Gurr et al., 1993; Minahan, 1996). Two major types of stateless nations exist today: those who live in democracies, such as the Quebecois in Canada and the Scots in the U.K., and those who live under oppressive regimes, such as the Kurds in Iran, Iraq, Syria, and Turkey. This study focuses on social science faculty who conduct research on the latter type of stateless nations.

Today, all stateless nations live in countries ruled by foreign governments. Most of these governments, however, do not represent the stateless nations, often persecute them, and deny their members the right of self-determination. For various reasons, governments that dominate stateless nations intentionally neglect to, or rarely, publish and disseminate information on and to these peoples. These governments also prohibit, or place restrictions on, the publication and dissemination of information on stateless nations. Even if these host governments publish, or allow the publishing of, any information about their own stateless nations, the information they disseminate or allow to be disseminated is exclusively prostate. As a result, researchers studying stateless nations often rely on other sources of information, such as nongovernmental organizations (e.g., Amnesty International and Minority Rights Group), international governmental organizations (e.g., the United Nations (UN) and the European Union (EU)), and governments of world powers (e.g., the U.S., Russia, U.K., France, and China). The information from these sources is largely antihost states - that is, a great part of it criticizes the powers that keep stateless nations from becoming states in their own right. This is especially true if the source government is an opponent to the host country. To illustrate, the U.S. government would heavily criticize the Iraqi government for its 
oppression of the Kurds, but it would not criticize the Turkish government as much for oppressing the Kurds because Turkey is an ally (Lawyers Committee for Human Rights, 1996). Some researchers also rely on information disseminated by the stateless nations' own social and political organizations, which, in many cases, operate underground and are underrepresented in the international community. For the purposes of this study, we chose to examine social science faculty studying one particular stateless nation, namely, the Kurds. Future studies may build on the findings of this paper by examining faculty researching other stateless nations.

The Kurds were selected here as a case study simply because they are commonly known as the world's largest stateless nation (McDowall, 1996). Today, they number more than 30 million people divided primarily among Turkey, Iran, Iraq, Syria, and the former Soviet Republics. Approximately 1 million Kurds live in Europe, and their number in the U.S. grew from 50 in 1975 to more than 15,000 in 1999 (Kurdish Institute of Paris, 2000; Meho, 2001).

The history of the Kurds is complicated, going back more than 4000 years. Until the nineteenth century, they enjoyed some type of independence, primarily in the form of principalities within larger empires. Following the disintegration of the Ottoman Empire in World War I, both Great Britain and France promised the Kurds an independent state in the Treaty of Sevres (signed August 10, 1920). However, later, Britain and France decided not to implement the Treaty and divided the Ottoman territories according to their own needs with Kurdistan apportioned to the new states of Turkey, Syria, and Iraq. The division of the Kurds and Kurdistan was formalized in the Treaty of Lausanne (signed June 24, 1923). This new treaty excluded any mention of the Kurds, let alone of their rights to self-determination. Since then, all expressions of Kurdish nationalism were put down by regional and international powers with extreme brutality and thoroughness (see McDowall, 1996).

Until 1932, the Kurdish areas in Iraq were ruled by a British administration that helped the Kurds foster their culture and traditions yet made every effort to crush any attempts at Kurdish independence. The British government also provided assistance to the Iranian and Turkish governments in their efforts to crush the Kurdish revolts that took place in the 1920s, 1930s, and 1940s. After World War II, both the U.S. and the Soviet Union became involved in shaping Kurdish history and politics. Soviet intervention in Kurdish politics was primarily observed in the role it played in the rise and fall of the Kurdish Republic of Mahabad (Iran) in 1946, as well as in its support of the Iraqi government against the Kurds and vice versa in the 1960s and 1970s. U.S. involvement in Kurdish history and politics started immediately after World War I when President Woodrow Wilson promised the Kurds and others the right to self-determination. That promise never materialized. After a lull of several decades, U.S. intervention in Kurdish politics regained intensity in the early 1970 s through its covert actions in the Kurdish war in Iraq. At the time, the U.S. Central Intelligence Agency (CIA) helped the Kurds in their waragainst the Iraqi government by providing them with arms through Iran. Suffering severe military setbacks by the Kurdish rebels, the Iraqi government decided to shift alliances from the Soviet Union to the West and concede some Iraqi land to Iran in return for the latter's termination of all support to the Kurds. As a consequence of Iraqi concessions, both the Iranian and U.S. governments decided to cease all military aid to the Kurds, a circumstance that led to their defeat in 1975. From the late 1980s on, both the UN and the EU assumed part of shaping Kurdish history and politics, primarily through raising human rights questions against the countries oppressing the Kurds (i.e., Iran, Iraq, Syria, 
and Turkey). Both the Iraqi chemical weapons attack on the Kurds in 1988 and the 1990-1991 Gulf war led to UN and EU's involvement in Kurdish affairs. The Gulf war has also led to an overt U.S. intervention in Kurdish affairs. This intervention continues to this date (see Kreyenbroek \& Sperl, 1992; McDowall, 1996).

This history of foreign rule and intervention resulted in, among other things, an immense number of government publications on the socioeconomic conditions, history, and politics of the Kurds that might be helpful to many researchers. These publications include primary materials, such as diaries, letters, and speeches of political and secret government officers meeting and/or visiting the Kurds and Kurdistan, maps, photographs, statistics, and government reports. These publications come from a wide range of sources and governmental bodies, for example, the U.S. Congress, Central Intelligence Agency, and Department of State, as well as U.K.'s Foreign Office, Air Ministry, and Colonial Office. In many cases, these publications represent the only sources of information on various aspects of Kurdish life (Hassanpour, 1992; Olson, 1989).

\section{Information-seeking behavior: social scientists}

There are numerous studies of the characteristics of social science information and the information-seeking activities of social scientists, both academic and nonacademic (e.g., Ellis, 1989, 1993; Ellis, Cox, \& Hall, 1993; Garvey, Lin, \& Nelson, 1970, 1971; Line, 1971, 1973, 1979, 1981; Line, Brittain, \& Cranmer, 1971). These and other more recent studies have, in turn, been extensively reviewed (e.g., Adam, 1982; Eager \& Oppenheim, 1996; Ellis, 1986; Hogeweg de Haart, 1983a, 1983b; Preschel \& Woods, 1989). This literature has, however, primarily focused on the information needs, seeking behavior, and use of scholars in the context of their departmental affiliation. In contrast, the information-seeking behavior of scholars in the context of their research topics has rarely been examined. It was this lack of specialized studies that motivated the examination of the information-seeking behavior of faculty studying stateless nations, a large group of information users that has never been exclusively dealt with in library and information science.

The works that investigated the information needs, seeking behavior, and use of social science faculty have found that when these faculty look for information (governmental and/or nongovernmental), they generally "rely heavily on citations identified in book and journal literature, on recommendations from colleagues, on personal collections and bibliographic files, and, in the more book-oriented disciplines, on browsing" (Stoan, 1991,p. 243). These works have also found that even though social scientists commonly use informal sources of information [e.g., conversation with colleagues, electronic mail (e-mail), and conferences], they do not have as a well-developed invisible college as do physical scientists. Social science faculty largely depend on formal sources of information, such as books and journals, for conducting research (Folster, 1989; Hart, 1993, 1997; Hernon, 1979a; Line, 1971, 1973; Line et al., 1971; Shoham, 1998).

Regarding what influences social science faculty and other people's information-seeking and use behaviors, studies have identified the impact of several factors, including the information seeker and his or her characteristics, the physical setting, the types of information sought, task complexity, the source of information, and the outcomes (Marchionini, 1995). With regard to government information in particular, studies have identified seven major 
factors that influence social science faculties' seeking behavior and use of such information, including: (1) the relevance of government information to one's research; (2) the importance of government information for one's research; (3) the researchers' familiarity or unfamiliarity with the arrangement of government publications in libraries; (4) the amount of time expended in searching for such materials; (5) the researchers' belief that governments publish little or nothing of value in their subject specialization; (6) the researchers' unawareness of the existence of relevant information in government publications; and (7) the unavailability of such publications to the scholars, a reason primarily found in studies conducted outside the U.S. (e.g., Hernon, 1979a, 1979b; Mooko \& Aina, 1998). For more details, see reviews by Caswell (1997) and Postema and Weech (1991).

The findings of previous studies provide a general picture of the manner in which social science faculty look for information and of the factors that influence their informationseeking behavior and information use. This study builds on these findings by describing the information-seeking environment of social science faculty studying the Kurds in the context of government information use. The study focuses on discussing new findings and on comparing these findings with relevant information-seeking activities from Ellis' behavioral model. Ellis carried out a few studies in which he used semistructured interviews for data collection and Glaser and Strauss's grounded theory for data analysis. His research resulted in a pattern of information-seeking behavior among social and physical scientists that included eight generic features or research activities (Ellis, 1989, 1993; Ellis et al., 1993):

- Starting: activities characteristic of the initial search for information, for example, identifying references, often by asking colleagues or consulting literature reviews and indexes and abstracts;

- Chaining: following chains of citations or other forms of referential connection between material;

- Browsing: casually looking for information in areas of potential interest. It not only includes scanning of published journals and tables of contents but also of references and abstracts of printouts from retrospective literature searches;

- Differentiating: using known differences (e.g., author and journal hierarchies) between sources as a way of filtering the amount and nature of information obtained;

- Monitoring: maintaining awareness of developments in an area through regularly following particular sources;

- Extracting: selectively identifying relevant material in an information source;

- Verifying: activities associated checking the accuracy of information; and

- Ending: activities characteristic of information seeking at the end of a topic or project, for example, during the preparation of papers for publication.

\section{Methodology}

In order to learn and understand how social science faculty studying the Kurds look for government information and what factors influence their seeking behavior and use of such 
information, the study used two methods for data collection: survey and citation analysis. A follow-up inquiry on certain questionnaire items was also used to get more in-depth information from the study participants.

\subsection{The questionnaire}

Several studies on the use and nonuse of government publications and on the information-seeking behavior of social science faculty were consulted, and their instruments were critically examined. Materials or questions from these instruments and the personal knowledge of authors were used to develop a questionnaire for this study. The questionnaire was composed of 25 questions with an option to express any additional comments regarding use and nonuse of government information and library resources and services. The study participants were asked about approaches and preferences for finding government information, reasons for use and nonuse of government information, use of libraries, barriers to the use of government information, and characteristics of government information used. The questionnaire was first distributed to four Library and Information Science faculty and doctoral candidates to assess any strengths and weaknesses and to ensure that all pertinent variables were included. After making necessary modifications, the questionnaire was sent in January 1998 to as many social science faculty as could be identified.

The faculty who participated in this study were identified and located using multiple sources and methods, including: (1) specialized directories, such as the Middle East Studies Association of North America's (1995) Directory of Members; (2) biographical information found in published books and articles that were, in turn, located by searching more than a dozen databases and published bibliographies; ${ }^{1}$ and (3) snowballing. Using these sources and methods, 21 potential participants were identified. These participants were asked to return their questionnaires as soon as possible. After a 4-week time period, the same questionnaire was sent again to nonrespondents. A final query was sent in March 1998. All 21 potential participants returned their questionnaire; however, only 20 questionnaires were usable, as one respondent was not a faculty member of any institution.

\subsection{The study population}

The population was social science faculty conducting research on the Kurds and affiliated with western academic institutions (in this case, colleges and universities located in Australia, Canada, New Zealand, Turkey, the U.S., and European countries located to the west of the Czech Republic, Hungary, Poland, Russia, Slovak Republic, and Slovenia). Seven of the participants were political scientists, five interdisciplinary, four anthropolo-

\footnotetext{
1 Databases used include: Abstracta Iranica, Anthropological Index Online, Anthropological Literature, Historical Abstracts, Index Islamicus, International Political Science Abstracts, PAIS International, Political Science Abstracts, Social Sciences Citation Index, Sociological Abstracts, and OCLC's WorldCat. Bibliographies used included: Meho (1997) and Meho and Maglaughlin (2001).
} 
gists, three historians, and one geographer. The members of the interdisciplinary group primarily conducted research in and identified themselves as members of two or more of the following fields: anthropology, communication, education, history, linguistics, politics, religion, sociology, and women's studies. Half of the participants were members of ethnic studies and area studies programs in their respective universities. The other half were members of individual departments. In terms of professional rank, six of the participants were assistant professors, nine were associate professors, and five were professors. Geographically, five of the participants were located in the United States, four in the U.K., three in Germany, two in Canada, and one in each of Australia, France, Italy, the Netherlands, Switzerland, and Turkey. The participants were also classified according to the frequency of their use of government information. Because the frequency of faculty use of a library's document collection was previously found not to be a good indicator of government information use (e.g., Hernon, 1979b), the participants were asked to rate themselves as heavy users, moderate users, infrequent users, or nonusers. A heavy user was defined for the participants as a person who uses government materials in all or most of her/ his publications $(67 \%$ or above). A moderate user is a person who uses such materials in half of her/his publications (around 50\%). An infrequent user is a person who uses government materials in very few (less than $25 \%$ ) of her/his publications. A nonuser is a person who never uses government publications in her/his research. Results showed that five participants defined themselves as heavy users, six as moderate users, seven as infrequent users, and two as nonusers.

\subsection{Citation analysis}

For the purposes of citation analysis, a list of all of the participants' published books and referreed journal articles on the Kurds was compiled. Several databases and published bibliographies were used to collect this information. ${ }^{2}$ The total number of works compiled for all participants was 220 . Because the number of publications from one participant to the other varied considerably (range $=27$, median $=5$ ), we decided to examine only a sample of the scholars' publications. This was done to reduce the impact a highly skewed distribution of papers examined might have across participants. We examined all of the publications of the participants who published five or fewer works and made a selection from those participants who published more than five as follows: when two papers were investigating the same topic, the more recent item was kept. Articles that were later published as chapters in books or were published in other journals under different titles were also dropped. The total number of works examined was 111 (100 journal articles and 11 books), representing an average of 5.5 works per participant. From examining the references of these 111 works, 7,379 unique citations or references were identified, $653(8.8 \%)$ of these were to government publications. 


\section{Results}

\subsection{Methods used for locating government information}

Study participants that use government information $(n=18)$ were asked to indicate how they locate the government information they need for, and/or use in, their research. The majority $(94.4 \%)$ reported that they do so by finding citations to government information in other works. This was followed by asking, or receiving information from, colleagues $(72.2 \%)$ and consulting university online catalogs $(61.1 \%)$, electronic indexes and databases $(50.0 \%)$, and printed indexes (33.3\%). One-third mentioned that they use both the World Wide Web (Web) and electronic-mailing lists for locating such publications, and slightly over one-fifth referred to electronic-mailing lists only. ${ }^{3}$ In addition, $11.1 \%$ indicated that they contact relevant government offices directly, and another $11.1 \%$ find relevant government information among personal collections. The Web and electronic-mailing list users were all users of Turkish and U.S. current government information. This was not unexpected, given the fact that only the government information of these two countries is among the information that is both partially available online and is used by these participants. Virtually none of the information that is used and/or cited by users of information that originates from other governments is available online. Most of the relevant government information from other governments is historical and still available only in printed formats and located primarily in archives (see below). ${ }^{4}$

Study participants that use government information (users hereafter) were also asked to indicate whether they are reluctant to ask librarians for help in locating the government information they need or wish to have for their research on the Kurds. Two-thirds (or 12) of the respondents expressed no reluctance in doing so, while one-third (or six users) indicated that they are "sometimes" or "always" reluctant to ask librarians for help. Both groups of users were then asked to indicate what they ask for and why they are reluctant to ask for help, respectively. Respondents were asked to choose and specify all relevant answers. Of the users who indicated no reluctance to ask librarians for help,

- 10 reported that they primarily ask for assistance in finding materials or information to answer ready-reference type of questions;

- 9 indicated that they ask for assistance in locating publications not held by their libraries; and

- 6 pointed at asking for assistance in using electronic sources.

${ }^{3}$ Examples of indexes and abstracts used include: FBIS (Foreign Broadcast Information Service), Lexis/Nexis, and PAIS. Examples of Web sources mentioned include: Amnesty International (www.amnesty.org), GPO Access (www.access.gpo.gov), the Turkish Ministry of Foreign Affairs (www.mfa.gov.tr), and the UN (www.un.org). Examples of electronic-mailing lists mentioned include: trknws-1 (Turkish News listserv) and wki@kurd.org (the Washington Kurdish Institute).

${ }^{4}$ Based on the survey data as well as on an analysis of the references used in the papers and books published by the study participants and other researchers studying the Kurds (see also Meho \& Sonnenwald, 2000). 
As for the users who indicated that they are "sometimes" or "always" reluctant to ask librarians for help in finding needed government information,

- Four indicated that it was because their librarians appear not to be well informed about government publications;

- Three reported that it was because they feel reluctant to reveal a lack of knowledge about library materials and systems;

- Two indicated that consultation with library staff does not lead to the desired information;

- Two indicated that they do not need to ask librarians because they know how to locate the needed information; and

- Two attributed the reason to the librarians' lack of knowledge about the Kurds.

\subsection{Reasons for using government information}

Because persistence in searching for and using information depends on many factors, such as the perceived importance of that information, the urgency with which it is needed, and the perceived severity of the consequences of not having that information (Harris \& Dewdney, 1994), the users were first asked to indicate the degree of importance that government information has to their research on the Kurds: $44.4 \%$ reported that such information is "very important" and another $44.4 \%$ as "important." Only $11.1 \%$ of the users reported that government information is "not important" for their research on the Kurds. Both the frequency of use of government publications and the degree of importance were found to be related, and this relationship was highly significant (Spearman's $r=.563$, significant at .01 , two-tailed). Afterwards, the users were asked to highlight their reasons for using such information. About $72 \%$ indicated that they do so because government publications are primary sources of information on the Kurds. Others indicated that government publications provide information on the Kurds of historical value (66.7\%), contain specific information on the Kurds that cannot be obtained otherwise (61.1\%), and provide current information on the Kurds (61.1\%). Participants also made some additional remarks. For example, one mentioned that she or he uses government information because it is an "important source [of] official views and policies." Another participant said: "I rarely work on international relations. These documents however, are still very unique for understanding foreign policies, especially those of the U.S., U.K., France, UN ...."

\subsection{Reasons for infrequent use and nonuse of government information}

To learn about factors that influence the information-seeking behavior of participants who infrequently use (7) or never use (2) government information, they were asked to specify the reasons for their infrequent use or nonuse. These participants were given the option to choose more than one response. The two nonusers indicated that they do not use government information because they largely rely on fieldwork material and "conventional-book form information" and because government publications are not relevant to their research. The 
majority of infrequent users (six out of seven) reported that governments publish little or nothing of value to their research. Others indicated that it takes too much time to find relevant information in such publications (2), that existing indexing and abstracting tools for these publications are generally not accessible (2), and that the desired publications are not available in their college or university libraries (2). One infrequent user added: "I have my own archive and book collection of historical works and new titles. I add to this [collection] frequently." Another infrequent user wrote: "I am not aware of any public library in Europe that has a more than haphazard collection of relevant documents." The same person also wrote: "[relevant] government publications are not generally available in university libraries here [in Europe]."

\subsection{Barriers to the use of government information}

To obtain additional insights into factors that influence information-seeking behavior and use, study participants, were asked to identify barriers to their use of government information. A total of 8 of the 16 participants who answered this question indicated that the main barrier is the online catalog, that is, the catalog does not list all of the government materials acquired by their libraries. A similar number of participants mentioned that their libraries have small collections of government publications. Six (or 37.5\%) indicated that it is difficult to determine which publications their libraries have or do not have, and another six (or $37.5 \%$ ) pointed out that the classification scheme of government materials is confusing. It should be noted here that not all libraries around the world follow the same classification scheme for their collections of government publications. For example, many libraries use SuDoc for many U.S. government publications received through the depository library program, whereas many others use Library of Congress or Dewey classification systems for U.S. and other governments' publications, and still, others use different schemes for different documents or do not even classify documents at all. ${ }^{5}$

\subsection{Characteristics of government information used}

As mentioned earlier, studies have found that the information-seeking and information use behaviors of social science faculty and other people are influenced by, among other things, the nature or characteristics of the information needed. Therefore, to learn about any additional factors that influence the information-seeking behavior and information use of the study participants, we examined the origins of the government materials they utilized and their location and access methods. Table 1 shows that U.S., British, and Turkish government publications are the most frequently used by the study participants, and that the French, German, Iranian, and Italian government publications are the least frequently used. Results also show that $61 \%$ of the study participants (excluding the two nonusers) have used government information of at least three different countries or international organizations, and

\footnotetext{
5 This information is based on contacts made with two public libraries and 10 academic libraries that study participants have used for their research on the Kurds.
} 
Table 1

Number of participants using government information distributed by country of origin $(n=18)$

\begin{tabular}{lc}
\hline U.S. & 13 \\
British & 12 \\
Turkish & 10 \\
UN/LN & 7 \\
Iraqi & 6 \\
French & 2 \\
German & 2 \\
Iranian & 1 \\
Italian & 1 \\
\hline
\end{tabular}

$72 \%$ have used government information in two or more different languages (see Table 2 ). The participants as a whole have used government information from at least nine countries/ international governmental organizations and in more than seven languages.

Regarding the location and access methods of the government information used, results show that one-third of the user participants have exclusively used government information that is only available in national archives, particularly, the British Public Record Office (PRO), France's Archives Diplomatiques, and Italy's Archivio Storico del Ministero degli Affari Esteri (the Historical Archive of the Ministry of Foreign Affairs). Another one-third have used government information that is available online or in print and electronic formats in the participants' university libraries. The remaining one-third has used both archival and nonarchival government material. Results in this study also show that $83.3 \%$ of the users of archives travel to the location of information. The remaining $16.7 \%$ of the users either receive

Table 2

Diversity of government information used and/or cited by user participants

\begin{tabular}{lccc}
\hline $\begin{array}{l}\text { No. of countries } \\
\text { of origin }\end{array}$ & $\begin{array}{l}\text { \% of Participants } \\
\text { using }(n=18)\end{array}$ & $\begin{array}{l}\text { \% of Participants } \\
\text { citing }(n=16)\end{array}$ & $\begin{array}{l}\text { \% of Participants using } \\
\text { and/or citing }(n=18)\end{array}$ \\
\hline 7 & & & 6 \\
6 & 6 & 6 & 22 \\
5 & 33 & 19 & 39 \\
4 & 44 & 44 & 67 \\
3 & 61 & 63 & 78 \\
2 & 83 & 75 & 89 \\
1 & 100 & 100 & 100 \\
& & & \\
No. of languages & & 0 & 50 \\
\hline 4 & 11 & 25 & 83 \\
3 & 39 & 63 & 100 \\
\hline
\end{tabular}

Table to be read as follows: $61 \%$ of the user participants have used government information of three different countries; $63 \%$ of the users have cited government information in two different languages; $78 \%$ of the users have used and/or cited government information of three different countries; and $83 \%$ of the users have used and/or cited government information in two different languages. 
copies of needed materials through their libraries or directly from the archives, or cite them from other published secondary sources. Further discussion on the origins and other characteristics of government information used is provided below.

\subsection{Results from citation analysis}

Citation analysis was used to discover the frequency of government information cited by the participants and to identify the characteristics of these citations. Citation analysis was also used to compare results between survey data and citation data. As mentioned earlier, a total of 111 works of the participants were examined for their citations to government materials. The examination resulted in 7379 unique citations or references of which $8.8 \%$ were to government publications. Most of the other citations were to books, news items, and journal articles (see Table 3). Results also showed that $63.0 \%$ of the study participants that cited government information have cited information of at least three different governments and/or international organizations and $63.0 \%$ have cited government information in two or more different languages (see Table 2$)$. The participants as a whole $(n=16)$ have cited government information from at least 10 countries/international governmental organizations and in more than seven languages.

A classification of citations according to the number of participants who have cited each government's publications showed that both British and U.S. documents are cited by $62.5 \%$ of the participants. Other highly cited publications include UN and League of Nations (LN) sources $(50.0 \%$ of the participants). Slightly more than one-third of the participants cited Turkish and EU government documents, and very few cited French, German, Iranian, Iraqi, and Italian documents (see Table 4).

Table 3

Distribution of citations by type

\begin{tabular}{lrr}
\hline Type & Number of citations & $\%$ \\
\hline Books and monographs & 2847 & 38.6 \\
News $^{\text {a }}$ & 1476 & 20.0 \\
Journal articles & 1299 & 17.6 \\
Government publications & 653 & 8.8 \\
Chapters in books & 574 & 7.8 \\
Kurdish organizations publications & 137 & 1.9 \\
NGOs publications & 100 & 1.4 \\
Encyclopedia and dictionary articles & 99 & 1.3 \\
Unpublished dissertations & 83 & 1.1 \\
Interviews & 70 & 0.9 \\
Unpublished papers & 28 & 0.4 \\
Web resources & 0 & 0.0 \\
Other & 13 & 0.2 \\
Total & 7379 & 100.0 \\
\hline
\end{tabular}

\footnotetext{
a Includes newspaper and magazine articles, radio news, and press releases.
} 
Table 4

Number of participants citing each government's publications $(n=16)$

\begin{tabular}{ll}
\hline Government & No. of participants \\
\hline Great Britain & 10 \\
U.S. & 10 \\
UN and LN & 8 \\
Turkey & 6 \\
European Union & 5 \\
Iran & 3 \\
Iraq & 3 \\
France & 2 \\
Germany & 1 \\
Italy & 1 \\
\hline
\end{tabular}

5.7. Comparison of results between survey data and citation data

Although survey data and citation data measure two different things, a comparison between them can still be made that would allow learning more about the participants' information-seeking

Table 5

Comparison between citation data and survey data - origins of government publications used and/or cited

\begin{tabular}{|c|c|c|c|c|c|c|c|c|c|c|}
\hline $\begin{array}{l}\text { Parti- } \\
\text { cipant }\end{array}$ & British & U.S. & UN/LN & Turkish & Iraqi & EU & Iranian & French & German & Italian \\
\hline 1 & & $\checkmark$ & & $\bullet$ & & $\checkmark$ & & & & \\
\hline 2 & $\checkmark$ & $x$ & $\checkmark$ & $\checkmark$ & $x$ & & & $\bullet$ & & \\
\hline 3 & $\checkmark$ & $\checkmark$ & $\bullet$ & $\checkmark$ & $\times$ & $\checkmark$ & & & & \\
\hline 4 & $\checkmark$ & $\checkmark$ & & & $\checkmark$ & & $\bullet$ & & & \\
\hline 5 & $\checkmark$ & & $\bullet$ & & & & & $\checkmark$ & & \\
\hline 6 & $\checkmark$ & $\bullet$ & $\bullet$ & & & $\checkmark$ & & & & $\checkmark$ \\
\hline 7 & & $\checkmark$ & & $\bullet$ & $\bullet$ & & & & & \\
\hline 8 & $\checkmark$ & $\checkmark$ & $\bullet$ & $x$ & $\checkmark$ & $\checkmark$ & $\bullet$ & & & \\
\hline 9 & & $\checkmark$ & $\checkmark$ & $\checkmark$ & & $\checkmark$ & & & & \\
\hline 10 & $\checkmark$ & $\checkmark$ & $x$ & $\times$ & $\times$ & & & & & \\
\hline 11 & $x$ & $x$ & $x$ & $x$ & $\times$ & & $\checkmark$ & & & \\
\hline 12 & $\checkmark$ & $\checkmark$ & $\diamond$ & $\checkmark$ & & & & & & \\
\hline 13 & $\checkmark$ & $x$ & $\checkmark$ & $x$ & & & & & & \\
\hline 14 & $\checkmark$ & $x$ & & & & & & & & \\
\hline 15 & & & & $x$ & & & & & $\checkmark$ & \\
\hline 16 & & $\checkmark$ & & & & & & & & \\
\hline 17 & & & $x$ & & & & & & & \\
\hline 18 & $x$ & & $x$ & $x$ & & & & $x$ & $x$ & \\
\hline 19 & & & & & & & & & & \\
\hline Total & & $9 \checkmark$, & & & $2 \checkmark$ & $5 \checkmark$ & & & $1 \checkmark$, & $1 \checkmark$ \\
\hline & $2 \times$ & $\begin{array}{l}4 \times, \\
1\end{array}$ & $\begin{array}{l}4 \times \\
5\end{array}$ & $\begin{array}{l}6 \times \\
2\end{array}$ & $4 \times$ & & 2 & $\begin{array}{l}1 \times \\
1 \bullet\end{array}$ & $1 \times$ & \\
\hline
\end{tabular}

$\checkmark$ Indicated as used by the participant and was cited by him/her.

$\times$ Indicated as used by the participant but was not cited by him/her.

$\checkmark$ Cited by the participant but was not indicated as used by him/her. 
and using processes. In the survey, $90.0 \%$ of the participants claimed to use government information. These participants also indicated that they have used government information of nine different countries or sources (see Table 1). In citation analysis, $80.0 \%$ of the participants appeared to have cited government documents. Citation analysis also showed that participants cited documents of 10 different countries or sources (see Table 4). Of these countries or bodies, nine were the same as indicated on the survey as used. This is not to say that all or most of the participants have cited the government publications they have used or have used the publications they have cited. As a matter of fact, results show that $37.3 \%$ of the participants who indicated that they have used certain government publications did not cite them (see Table 5). Since this was found not to be a result of sampling error, ${ }^{6}$ the variation between use and citing pattern could be a result of the participants' not finding relevant information in those documents or of the participants' overindication of the identities of government documents they have used. ${ }^{7}$ Similarly, results show that $24.5 \%$ of the participants have cited more government publications than what they indicated as used, a discrepancy that could be attributed to the respondent's ability or inability to recall the identities of all the government publications she or he has used over the years or to the fact that the respondents have not used certain documents but cited them from other sources (see Table 5).

Another observation from comparing the survey data with citation data is that British and U.S. government documents were found the two most widely used and cited (see Table 5). In contrast, government documents of countries that persecute the Kurds (i.e., Iran, Iraq, and Turkey) were subject to major weeding or disregarding decisions. For example, of those respondents who indicated that they use Turkish government publications, only $40.0 \%$ have cited them. Similarly, of those respondents who indicated that they use Iraqi government publications, only $33.3 \%$ have cited them. The figures for British and U.S. documents were $83.3 \%$ and $69.2 \%$, respectively.

\section{Discussion}

This study describes the methods that social science faculty studying the Kurds use to locate relevant government information, and the factors that influence their seeking behavior and use of such information. Results show that these faculty employ similar methods for locating government information as other social science faculty, including: (1) asking, or receiving information from, colleagues; (2) finding relevant citations in other works; and (3)

\footnotetext{
${ }^{6}$ To assess the sampling error of the publications examined, we ran a test on the publications that were excluded from the sample. As mentioned earlier, for citation analysis, we examined all of the publications of the participants who published five or fewer works and made a selection from those participants who published more than five. So, for the test purposes, we randomly selected two publications of each of the participants who published more than five works. A total of 18 new items were examined for their citations. A comparison of results between the test's citation data and the survey data showed no difference with the results found earlier. That is, slightly over one-third of the participants do not cite the government publications they use.

7 According to Verhoeven (1990), it is well established in user survey research that there can be some discrepancy between what people do or know and what they say they do or know. Verhoeven (1990) provides several examples to support this claim.
} 
consulting university library catalogs and printed and electronic databases. These three methods constitute the major part of the "starting," "chaining," and "browsing" features of Ellis' behavioral model described earlier. The results of this study also show that the information-seeking behavior of social science faculty studying the Kurds is influenced by factors similar to those influencing other social science faculty, including: the belief that governments publish little or nothing of value to their research, the perceived importance of government information, the amount of time expended in searching for such information, the lack of access to indexing and abstracting tools, and the unavailability of government information to the scholars.

In addition to confirming some of the existing theories and findings as discussed above, this study also broadens our current understanding of theories on user needs and seeking behavior with three somewhat new findings: that social science faculty studying the Kurds are aware of, and use, new information technology; that accessing the needed materials is a major information-seeking activity; and that faculty examined here employ somewhat a more elaborate "differentiating" information-seeking activity than the one described in Ellis' behavioral model.

\subsection{Adoption of new information technology}

This study identified the use of two relatively new channels for locating government information that were not reported in earlier studies, namely, the Web and electronic-mailing lists. This was not surprising, given that most of the previous studies on the use of government information by social science faculty were conducted before the advent of the Web and the widespread use of electronic-mailing lists. This finding, however, suggests that in contrast to the general understanding that academic users and potential users of information are often unaware of sources and how to use them (Adams \& Bonk, 1995; Faibisoff \& Ely, 1976), a large proportion of social science faculty studying the Kurds (in this case, more than $55 \%$ of the users of government information) are aware of, and are adopting, new information technology to locate and use relevant government information. ${ }^{8}$ The participants' awareness of new information technology is not only evident by their knowledge and use of the Web and e-mail but also by their utilization of a wide range of other relevant electronic databases. More than $88 \%$ of the study participants indicated that they have used electronic resources in their research on the Kurds, including several core social science indexes and abstracts, such as Dissertation Abstracts International, Historical Abstracts, International Political Science Abstracts, PAIS, Social Sciences Citation Index, and Sociological Abstracts. Participants also named several other humanities and specialized databases, such as Abstracta Iranica, Arts and Humanities Citation Index, Index Islamicus, and Turkologischer Anzeiger.

Future research should try to examine the reasons for, and implications of, the somewhat high level of awareness and adoption rate of new information technology among the study

\footnotetext{
${ }^{8}$ It should be noted here that most if not all Kurds-related government information available on the Web or disseminated through e-mail is current in nature. Therefore, if we exclude those participants who do not use current information, the percentage of Web and e-mail users increases to more than $66 \%$.
} 
participants. Such examination might lead to ideas of how to better serve social science faculty, who are often unaware of new information technology and how to use it. Although further research is needed to identify the level of awareness and adoption of new information technology among the broader group of social science faculty studying stateless nations in general and not only the Kurds, the findings here suggest that libraries and other information centers must not only acquire or continue to acquire and provide access to government and other relevant information through traditional methods (i.e., the online catalog and print and electronic indexes) but also extend that to information found or made available on or through the Web. This provision of information services should also be associated with continuous equipment support that is needed to easily filter and rapidly organize the retrieved information. Finally, educating and/or informing nonuser faculty about relevant Web-based government information sources, as well as about the potentials of listservs for research purposes, is necessary because listing these resources on libraries' Web pages does not guarantee that they will be found used by researchers.

\subsection{Accessing}

According to David Ellis' behavioral model, eight categories seem sufficient to describe the information-seeking activities of social science faculty. These categories include: starting, chaining, browsing, differentiating, monitoring, extracting, verifying, and ending (see Literature review). While this model could successfully describe most of the informationseeking activities employed by the study participants, results here suggest that one particular category is missing from the model, that is, accessing.

The fact that most of the study participants have reported about access problems as barriers to using government information (e.g., unavailability of desired publications at own university library) suggests that accessing the information located through "starting" and "chaining" constitutes one of the major information-seeking categories of social science faculty examined here. The activities subsumed under this category are those methods used to access or obtain the materials needed to complete a particular research activity. These methods include among others: borrowing or photocopying material from own university library, interlibrary loan requests, subscribing to relevant publications or listservs, direct contact with the source of information (e.g., people and organizations), and traveling to the location of the needed material.

Although the majority of these methods are part of most researchers' information-seeking activities, traveling to the location of needed material is in particular a major activity performed by the study participants. As mentioned earlier, two-thirds of the participants have used government information that is exclusively found in archives and more than $83 \%$ of these users have traveled to those archives. These findings not only demonstrate the importance of archives to social science faculty studying the Kurds but they also call for a more practical and convenient method of accessing archived government information than traveling to its locations. The burdens of overseas travel on many researchers are insurmountable in terms of time and funding requirements alone. Although one could expect that the dissemination of Kurds- and other stateless nations-related archival materials through the Web would increase their use by scholars, further research is required to verify this. 


\subsection{Differentiating}

In addition to proposing a new category to Ellis' information-seeking behavior model, this paper suggests a modified type of "differentiating" category in the model. According to Ellis, differentiating is an activity that uses known differences between sources as a way of filtering the amount and nature of information obtained. His category of differentiating focuses on author and journal hierarchies and on the topicality of information to one's research as the bases of differentiating. However, this study shows that the criteria used in studying the Kurds to differentiate between sources include other factors as well, particularly the ideological perspective of the information found.

As mentioned earlier, many of the government publications used and/or cited by the study participants are pro-Kurdish in nature while others are anti-Kurdish. Consequently, researchers using these publications may make many weeding and disregarding decisions on the basis of their pro- or anti-Kurdish slogans rather than their topic relatedness or any other criteria. This could explain why information published by governments that persecute the Kurds (in this case, the Iranian, Iraqi, and Turkish governments) is not cited as frequently as it is used, whereas information published by the U.S. government, for example, is cited almost as frequently as it is used by the study participants. There could be several other reasons why some government information is used but not cited. Although further research is required to verify this, the fact remains that the source government or the origin of materials used by researchers is another important criterion that social science faculty might use to differentiate between sources.

\section{Conclusion}

This study has provided insight into the information-seeking behavior of social science faculty studying the Kurds, a group that has not received attention in information-seeking studies. In particular, the information-seeking behavior of these faculty was examined in the context of their use and nonuse of government information. Results of the study showed that these scholars employ similar methods for locating relevant information as other social science faculty. Results also showed that the main reason for, or barriers to, the use and nonuse of government information was not due to the faculties' knowledge or lack of knowledge about information services and sources but was due to deficient library collections and services. This suggests that libraries need to both periodically investigate the information needs of their faculty users and occasionally assess the adequacy of their collections and services in order to better serve these faculty.

A major portion of the information used by many of the study participants is exclusively found in archives. Another major portion is found online. While it probably is futile to think that the campus library system can, or ought, to play an aggressive role in meeting the information needs of the faculty that use foreign archival materials, libraries can and should strengthen their educational programs to acquaint faculty, especially nonusers, with relevant, newly emerging Web-based government information sources. The impact of disseminating archival material through the Web remains to be seen. 
In terms of the contributions of this study to theory and methodology, this study showed that accessing needed material is a major information-seeking activity that should be added to Ellis' behavioral model. The study also showed that the faculty examined here employ a somewhat more elaborate "differentiating" information-seeking activity than the one described in that same model. Despite that, more studies with more diversified and larger population sizes are needed to establish the generalizability of these results. These studies should also consider in-depth interviews as a primary method for data collection.

Finally, it is worth noting that this paper has discovered some elements that suggest that the study of the Kurds is inherently interdisciplinary. This interdisciplinarity, which is similar to what Westbrook (1999) has found in her work on women's studies faculty, is evident in at least two ways. First, not only have $25 \%$ of the study participants described themselves as interdisciplinary researchers, but half of the participants are members of different ethnic studies and area studies programs in their respective universities. Second, the research published by most of the faculty is diverse both in terms of the topics discussed and the places of publication. Although the interdisciplinary character of Kurdish studies is also demonstrated by the scatter and diverse nature of the government information used by the study participants, further research is required to support this claim and discuss its implications on theory and practice. In particular, future research should focus, among other things, on how often scholars studying the Kurds and other stateless nations are engaged in borrowing from fields other than their own and on the scholars' comments on the subject (i.e., on the interdisciplinary character of their research).

\section{References}

Adam, R. (1982). Language and information retrieval in the social sciences. Aslib Proceedings, 34, 394-405.

Adams, J. A., \& Bonk, S. C. (1995). Electronic information technologies and resources: use by university faculty and faculty preferences for related library services. College \& Research Libraries, 56, 119-131.

Caswell, T. R. (1997). Studies on government publications' use, 1990-1996. Government Information Quarterly, 14, 363-371.

Eager, C., \& Oppenheim, C. (1996). An observational method for undertaking user needs studies. Journal of Librarianship and Information Science, 28, 15-23.

Ellis, D. (1986). Social science information research. Journal of the American Society for Information Science, $37,86-88$.

Ellis, D. (1989). A behavioral approach to information retrieval system design. Journal of Documentation, 45, $171-212$.

Ellis, D. (1993). Modeling the information-seeking patterns of academic researchers: a grounded theory approach. Library Quarterly, 63, 469-486.

Ellis, D., Cox, D., \& Hall, K. (1993). A comparison of the information seeking patterns of researchers in the physical and social sciences. Journal of Documentation, 49, 356-369.

Faibisoff, S. G., \& Ely, D. P. (1976). Information and information needs. Information Reports and Bibliographies, $5(5), 2-16$.

Folster, M. B. (1989). A study of the use of information sources by social science researchers. The Journal of Academic Librarianship, 15, 7-11.

Garvey, W. D., Lin, N., \& Nelson, C. E. (1970). Communication in the physical and the social sciences. Science, 170, $1166-1173$. 
Garvey, W. D., Lin, N., \& Nelson, C. E. (1971). Scientific communication behavior of social and physical scientists. International Social Science Journal, 23, 256-271.

Gurr, T. R. (1993). Minorities at risk: a global view of ethnopolitical conflicts. Washington, DC: United States Institute of Peace Press.

Harris, R. M., \& Dewdney, P. (1994). Barriers to information: how formal help systems fail battered women. Westport, CT: Greenwood Press.

Hart, R. L. (1993). The information-gathering behavior of the faculty of a four-year state college. Unpublished doctoral dissertation, University of North Carolina at Chapel Hill.

Hart, R. L. (1997). Information gathering among the faculty of a comprehensive college: formality and globality. The Journal of Academic Librarianship, 23, 21-27.

Hassanpour, A. (1992). Nationalism and language in Kurdistan, 1918-1985. San Francisco, CA: Mellen Research Univ. Press.

Hernon, P. (1979a). Use of government publications by social scientists. Norwood, NJ: Ablex Pub.

Hernon, P. (1979b). Infrequent use and non-use of government publications by social scientists. Government Publications Review, 6, 359-371.

Hogeweg de Haart, H. P. (1983a). Characteristics of social science information: a selective review of the literature: part I. Social Science Information Studies, 3, 147-164.

Hogeweg de Haart, H. P. (1983b). Characteristics of social science information: a selective review of the literature: part II. Social Science Information Studies, 4, 15-30.

Johansson, E. (1982). The definition of official publications. IFLA Journal, 8, 393-395.

Kreyenbroek, P. G., \& Sperl, S. (Eds.). (1992). The Kurds: a contemporary overview. London, UK: Routledge.

Kurdish Institute of Paris (2000). Kurdish Institute of Paris home page. Paris, France: Kurdish Institute of Paris [resource on the World Wide Web]. URL: (〈http://www.institutkurde.org/homea.htm $\rangle)$ (accessed via the Internet, August 9).

Lawyers Committee for Human Rights (1996). Critique: review of the U.S. Department of State's country reports on human rights practices for 1996. New York: Lawyers Committee.

Line, M. B. (1971). The information uses and needs of social scientists: an overview of INFROSS. Aslib Proceedings, 23, 412-434.

Line, M. B. (1973). Information needs of the social sciences. INSPEL, 8 (2), 29-39.

Line, M. B. (1979). The influence of the type of sources used on the results of citation analyses. Journal of Documentation, 35, 265-284.

Line, M. B. (1981). The structure of social science literature as shown by a large-scale citation analysis. Social Science Information Studies, 1, 67-87.

Line, M. B., Brittain, J. M., \& Cranmer, F. A. (1971). Information requirements of researchers in the social sciences. Research Reports, 1-5. Bath, England: Bath University Library.

Marchionini, G. (1995). Information-seeking in electronic environments. New York: Cambridge Univ. Press.

McDowall, D. (1996). A modern history of the Kurds. London, UK: I.B. Tauris.

Meho, L. I. (1997). The Kurds and Kurdistan: a selective and annotated bibliography. Westport, CT: Greenwood Press.

Meho, L. I. (2001). The Kurds and Kurdistan: a general background. In: L. I. Meho, \& K. Maglaughlin (Eds.), Kurdish culture and society: an annotated bibliography (pp. 3-26). Westport, CT: Greenwood Press.

Meho, L. I., \& Maglaughlin, K. L. (2001). Kurdish culture and society: an annotated bibliography. Westport, CT: Greenwood Press.

Meho, L. I., \& Sonnenwald, D. H. (2000). Citation ranking versus peer evaluation of senior faculty research performance: a case study of Kurdish scholarship. Journal of the American Society for Information Science, $51,123-138$.

Middle East Studies Association of North America (1995). Directory of members. Tucson, AZ: Middle East Studies Association of North America.

Minahan, J. (1996). Nations without states: a historical dictionary of contemporary national movements. Westport, CT: Greenwood Press.

Mooko, N. P., \& Aina, L. O. (1998). The use of government publications: the case of social scientists at the University of Botswana. Journal of Government Information, 25, 359-365. 
Olson, R. W. (1989). The emergence of Kurdish nationalism and the Sheikh Said Rebellion, 1880-1925. Austin, TX: University of Texas Press.

Postema, B., \& Weech, T. L. (1991). The use of government publications: a twelve-year perspective. Government Publications Review, 18, 223-238.

Preschel, B. M., \& Woods, L. J. (1989). Social science information. Annual Review of Information Science and Technology, 23, 267-292.

Shoham, S. (1998). Scholarly communication: a study of Israeli academic researchers. Journal of Librarianship and Information Science, 30, 113-121.

Stoan, S. K. (1991). Research and information retrieval among academic researchers: implications for library instruction. Library Trends, 39, 238-257.

Verhoeven, S. M. (1990). User surveys. In: A. Kent (Ed.), Encyclopedia of library and information science, (vol. 45, pp. 373-399). New York: Marcel Dekker.

Westbrook, L. (1999). Interdisciplinary information seeking in women's studies. Jefferson, NC: McFarland.

Wilson, T. D. (2000). Human information behavior. Informing Science, 3 (2), $49-55$. 